\title{
Assessing Global Learning Outcomes
}

\author{
Gary R. Pike
}

Over the past year, I had an opportunity to chair a student's doctoral dissertation dealing with the assessment of students' global learning outcomes. I have to confess that before this past year I had not thought much about intercultural competence beyond its applications to effective functioning in American society. I knew effective functioning in a global society was important, but I did not realize how important it has become in higher education in the United States. Reading the dissertation was an education for me. Global competence is critical in order for graduates to be effective members of a workforce that will be able to compete effectively in today's economy. Developing the global competence of college graduates has led to increased emphasis on recruiting and enrolling international students, expanding study abroad and international service learning, and internationalizing college curricula. While these initiatives are not new, assessing their effectiveness is a topic that has come to prominence in the past decade.

A quick Google search reveals that a variety of tools are available to assess students' global learning and global competence. The Association of American Colleges and Universities (AAC\&U) has developed an “Intercultural Knowledge and Competence” VALUE rubric, and the AAC\&U publication Assessing Global Learning: Matching Good Intentions with Good Practice (McTighe Musil 2006) includes a sample survey for evaluating global learning outcomes. More recently, NAFSA: Association of International Educators (originally the National Association for Foreign Student Advisers) published a resource book, Improving and Assessing Global Learning (Green 2013), which includes information on assessing global learning, as well as three institutional assessment case studies—Juniata College, Georgia Institute of Technology, and Florida International University.

This is the author's manuscript of the article published in final edited form as:

Pike, G. R. (2017). Assessing Global Learning Outcomes. Assessment Update, 29(3), 8-9.

https://doi.org/10.1002/au.30095 
In addition to national associations, many colleges and universities are providing information about assessing global learning outcomes. For example, the Center for Research on Learning and Teaching at the University of Michigan (Center for Research on Learning and Teaching 2016) and Global Partnership Services at Texas A\&M University (Global Partnership Services 2017) have websites with links to a variety of instruments that can be used to assess global learning outcomes. Several institutions, including Becker College (2017) and Purdue University (Center for Instructional Excellence 2013), also have websites describing their efforts to promote global learning on their campuses.

Although these resources provide a variety of links to established measures of global learning, the measures are stand-alone assessments. That is, colleges and universities can use the assessments to accurately and appropriately map the status of global learning on their campuses, and they may even be able to assess gains in global learning using carefully designed pre- and post-test designs. What is lacking in these instances is the ability of a college or university to gauge how it compares to other colleges and universities. The Global Engagement Survey being developed by globalsl.org (Reynolds and Hartman 2016) may offer the possibility of baseline data.

The Global Engagement Survey (GES) is based on global learning outcomes identified by Hovland (2014) in cooperation with AAC\&U and NAFSA: Association of International Educators. The pilot study for the survey was conducted in 2014 and involved ten colleges and universities. Results of the pilot were used to revise the survey, and the most recent version of the survey was administered at eight institutions. The institutions had sixty different summer programs designed to foster global learning. The published report on the most recent survey administration is based on the responses of 107 students who completed both pre- and post-test versions of the survey before and after program participation.

Borrowing from established surveys of intercultural learning, civic engagement, and critical thinking, the GES consists of seven scales: (1) Intercultural Competence-Communication, (2) Intercultural Competence-Self-Awareness, (3) Civic Engagement-Efficacy, (4) Civic Engagement-Political Voice, (5) Civic Engagement-Conscious Consumption, (6) Civic Engagement-Values, and (7) Critical Reflection. 
An interesting feature of the GES is that it includes thirteen open-ended items, as well as sixty typical closed items. A typical closed (Likert) item is "I am very comfortable talking about diversity with people of different cultures." Open-ended items build off of the closed items. For example, for the preceding question, students who responded "Strongly Agree” or “Agree” were asked "Could you describe a point at which you get uncomfortable discussing diversity with people of different cultures?” Students who responded “Strongly Disagree” or “Disagree” were asked “Can you indicate why you are uncomfortable discussing diversity with people of different cultures?" The open-ended items allow for qualitative assessment of program strengths and opportunities for improvement.

Information on scale reliability is not available in the survey report. Scale scores were related to student demographic characteristics, such as gender, prior volunteer experience, and parents' education; scores were also correlated with program features such as presence of a program leader on site with students, program location, and whether the program included a service-learning component.

Obviously, GES is still in its infancy. For 2017-2018, the survey's developers are interested in expanding participation and providing participating colleges and universities with opportunities to customize parts of the GES to better suit their needs. Depending on the course of survey development, the GES may offer an opportunity for institutions to influence the content of the survey, and to collect baseline information about global learning outcomes nationally.

\section{Biography}

- Gary R. Pike is professor of higher education and student affairs in the Indiana University School of Education at Indiana University-Purdue University Indianapolis. His e-mail address is pikeg@iupui.edu. 


\section{References}

Becker College. 2017. Global Learning and Student Outcomes. Worcester, MA: Becker College. https://www.becker.edu/global/global-citizenship/terminology-working-definitions/global-learningstudent-outcomes

Center for Instructional Excellence. 2013. The Global Learning Faculty and Student Development Program. West Lafayette, IN: Purdue University. http://www.purdue.edu/cie/learning/global/

Center for Research on Learning and Teaching. 2016. Tools for Assessing Intercultural and Global Competence. Ann Arbor, MI: The Regents of the University of Michigan. http://www.crlt.umich.edu/interculturalcompetence

Global Partnership Services. 2017. Resources for Assessing Global Learning. College Station, TX: Texas A\&M University. http://globalsupport.tamu.edu/Assessment/External-documents/Resources-forAssessing-Global-Learning

Green, M. F. 2013. Improving and Assessing Global Learning. Washington, D.C.: NAFSA Association of International Educators. http://www.nafsa.org/_file/_/improving_assessing.pdf

Hovland, K. 2014. Global Learning: Defining, Designing, Demonstrating. Washington, D.C.: Association of American Colleges and Universities.

https://aacu.org/sites/default/files/files/Global/global_learning_2014.pdf

McTighe Musil, C. 2006. Assessing Global Learning: Matching Good Intentions with Good Practice. Washington, D.C.: Association of American Colleges and Universities. http://archive.aacu.org/SharedFutures/documents/Global_Learning.pdf.

Reynolds, N. P., and E. Hartman. 2016. Assessing Global Learning. globalsl.org. 